\title{
Mechanism of Stress Relief Cracking in a Granular Bainitic Steel
}

\author{
Zai-Song Yu ${ }^{1,2} \cdot$ Jian-Xun Zhang ${ }^{1} \cdot$ Hong-Zhe Wang ${ }^{2} \cdot$ Rong-Can Zhou ${ }^{2} \cdot$ Yong Yuan $^{2}$
}

Received: 4 July 2016/Revised: 24 August 2016/Published online: 27 October 2016

(C) The Chinese Society for Metals and Springer-Verlag Berlin Heidelberg 2016

\begin{abstract}
Coarse-grained heat-affected zone (CGHAZ) of a low alloyed, granular bainitic steel T24 was simulated in a Gleeble apparatus. The stress relief of the CGHAZ was analyzed by annealing the samples. The morphology and behavior of the microstructure near the grain boundaries during stress relief were investigated by means of focused ion beam, in situ tensile testing, transmission electron microscopy, scanning electron microscopy and electron back-scatter diffraction. It was observed that there were large martensite/austenite islands distributed along the grain boundaries of CGHAZ. During stress relief at elevated temperature, the retained austenite at the grain boundaries decomposed into $M_{3} \mathrm{C}$ carbides and a ferrite forming softening zone. Together with the stress relief, piled up of dislocations occurred within the ferrite in the area adjacent to the ferrite $/ M_{3} \mathrm{C}$ interface, which resulted in high level of stress accumulation and caused crack initiation along the grain boundaries. These results indicate that the stress relief induced the grain boundary crack is controlled by other mechanisms rather than the creep-like grain boundary sliding.
\end{abstract}

\section{KEY WORDS: Granular bainitic steel; Heat-affected zone; Stress relief cracking; Martensite/austenite island; Behavior of grain boundary}

\section{Introduction}

Stress-relief cracking (SRC) is a major cause of weld failures in creep resistant, precipitation strengthened materials, such as ferritic steels, stainless steels, and Nibased super alloys [1]. The cracking usually occurs in the heat-affected zone, which is the most susceptible area for crack initiation, due to solid-state metallurgical reactions during both heating and cooling thermal cycles [2]. SRC

Available online at http://link.springer.com/journal/40195

Zai-Song Yu

yuzaisong@tpri.com.cn

1 State Key Laboratory for Mechanical Behavior of Materials, Xi' an Jiaotong University, Xi' an 710049, China

2 Xi'an Thermal Power Research Institute Co. Ltd., Xi'an 710032, China and premature cracking in these materials are the types of intergranular cracking that occur following postweld heat treatment and during exposure to elevated temperatures $\left(\sim 550{ }^{\circ} \mathrm{C}\right)$.

To date, many investigations have been performed to understand the SRC mechanisms. Typically, there are two well-known cracking mechanisms. The first is the formation of a precipitation free zone, resulting in local weakening and strain localization. The cracking mechanism was explained by the combination of a precipitation strengthened matrix and a soft precipitation free zone, formed adjacent to prior austenite grain boundaries [3-5]. The second is the creep-like grain boundary (GB) sliding that causes micro-void formation along the GBs and the triple point junctions. For example, the segregation of impurities to the prior austenite GBs may lower the cohesive strength of GBs and cause intergranular cracking through GB sliding [6-8]. It has also been reported that intergranular cracking takes place by the traditional creep failure 
mechanism in which cavities open along GBs and then coalesce to form a continuous crack [9-14].

Although many SRC mechanisms have been widely explored, the topic still remains debatable. There is still considerable work that needs to be done on boundary morphologies and corresponding behavior to avoid SRC problem. The alloy T24 is a type of $2.25 \mathrm{Cr}-1 \mathrm{Mo}$ granular bainitic steel and a promising candidate for applications in membrane water walls in ultra-supercritical (USC) coal-fired power plants [15]. However, T24 is susceptible to SRC, which limits its applications range. In this study, the mechanism of SRC in a T24 alloy was investigated through thermal simulation, stress relaxation testing and detailed microstructural characterization. The findings are beneficial to better understanding the SRC mechanisms.

\section{Experimental}

The commercial steel T24 was supplied in a form of tubes by Vallourec \& Mannesmann (V\&M), Germany. All the specimens were cut from the as-received tubes. The chemical composition of T24 is listed in Table 1. As-received T24 was heat treated as follows: austenitization at $1000{ }^{\circ} \mathrm{C}$ for $20 \mathrm{~min}$, followed by air cooling; the subsequent tempering was conducted at $750{ }^{\circ} \mathrm{C}$ for $2 \mathrm{~h}$.

The coarse-grained heat-affected zone (CGHAZ) simulation and stress relaxation testing were performed using Gleeble techniques. A Gleeble 3800 apparatus was used for these experiments. The peak temperature was set to be at $1350{ }^{\circ} \mathrm{C}$ and the cooling time $\left(t_{8 / 5}\right)$ to $40 \mathrm{~s}$. The curve of the temperature as a function of time during thermal simulation is presented in Fig. 1. For the specimen following the welding thermal simulation, the scratch lines of $20 \mu \mathrm{m}$ in length across GB were marked using FEI NOVA 200 Nano Lab scanning electron microscope (SEM) with a focused ion beam (FIB), as observed in Fig. 2. Then, the specimen with scratch lines was used for compressive stress relaxation testing, as illustrated in Fig. 3. The time of stress relief was up to $100 \mathrm{~min}$ at $550{ }^{\circ} \mathrm{C}$. Additionally, for studying the microstructural evolution, one sample was annealed at $550{ }^{\circ} \mathrm{C}$ for $400 \mathrm{~h}$ in a furnace. Hardness and microhardness Vickers of the specimens was performed using a load of 98 and $0.098 \mathrm{~N}$, respectively, with a dwell time of $10 \mathrm{~s}$ in both cases.

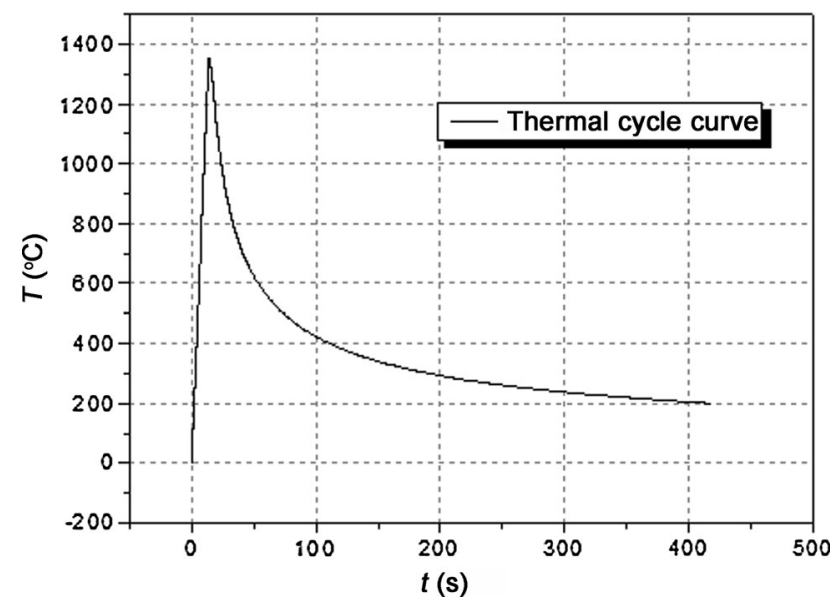

Fig. 1 Curve of the temperature as a function of time during thermal simulation using a Gleeble 3800 apparatus

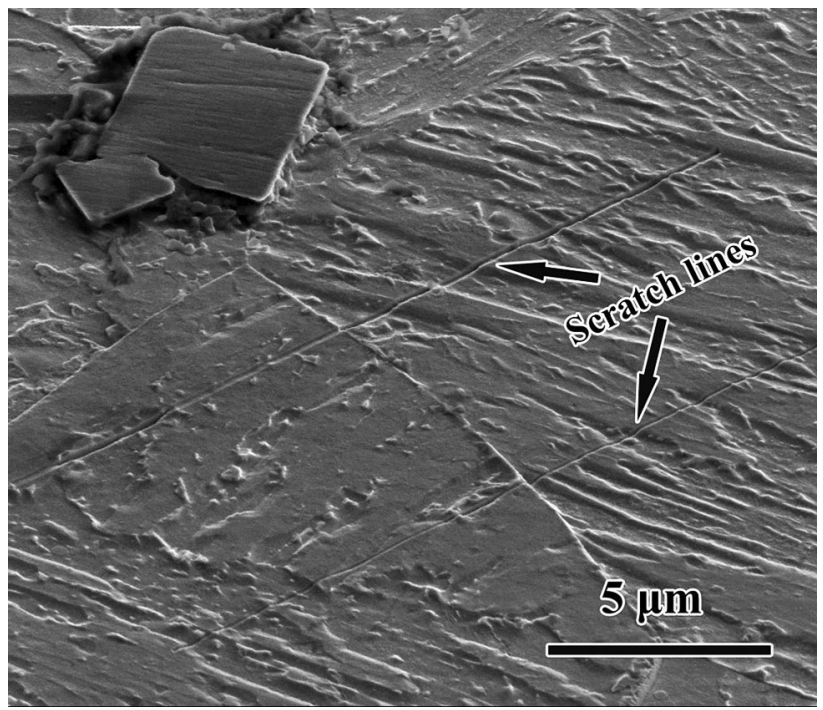

Fig. 2 SEM image showing the scratch lines of approximately $20 \mu \mathrm{m}$ in length across GB, marked by a FEI NOVA 200 Nano Lab $\mathrm{SEM} / \mathrm{FIB}$

The specimen for in situ tensile testing was annealed at $650{ }^{\circ} \mathrm{C}$ for $10 \mathrm{~h}$. The specimen had a thickness of $0.5 \mathrm{~mm}$, as schematically demonstrated in Fig. 4. The in situ tensile testing was carried out in an FEI Quanta 400F SEM at room temperature, at a rate of $6.67 \mu \mathrm{m} \mathrm{s}^{-1}$. SEM and transmission electron microscopy (TEM) were employed for the observation on the microstructural features, especially the GBs. For electron back-scatter diffraction

Table 1 Chemical composition of T24 (wt\%)

\begin{tabular}{llllllllllllll}
\hline $\mathrm{C}$ & $\mathrm{Si}$ & $\mathrm{Mn}$ & $\mathrm{P}$ & $\mathrm{S}$ & $\mathrm{Cr}$ & $\mathrm{Mo}$ & $\mathrm{V}$ & $\mathrm{Ni}$ & $\mathrm{N}$ & $\mathrm{Nb}$ & $\mathrm{Ti}$ & $\mathrm{B}$ & $\mathrm{Fe}$ \\
\hline 0.06 & 0.33 & 0.68 & 0.012 & 0.0016 & 2.29 & 0.97 & 0.24 & 0.11 & 0.008 & 0.054 & 0.08 & 0.003 & $\mathrm{Bal}$. \\
\hline
\end{tabular}




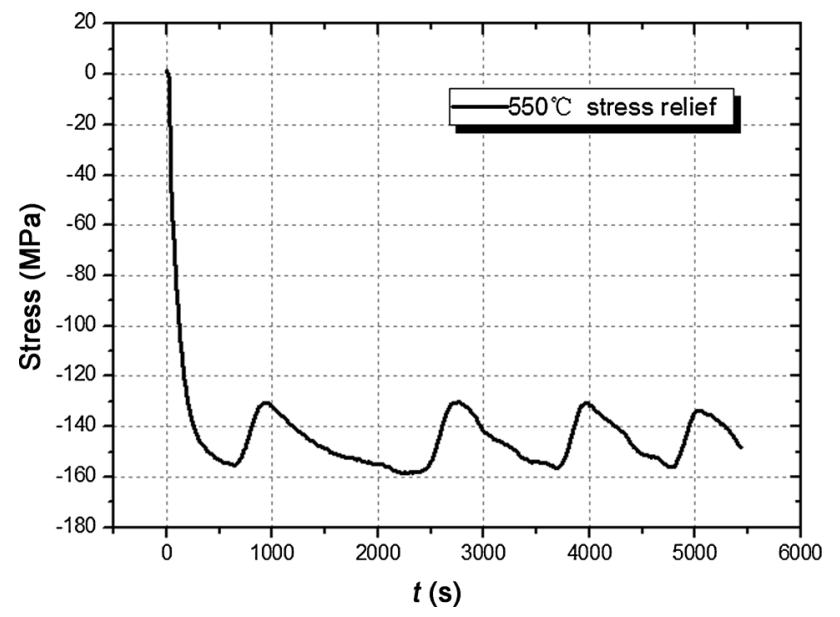

Fig. 3 Plot of compressive stress as a function of time at $550{ }^{\circ} \mathrm{C}$ showing the stress relaxation

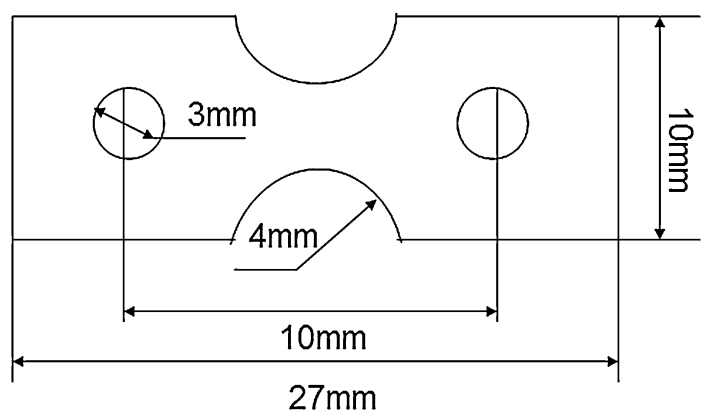

Fig. 4 Schematic drawing of the specimen, $0.5 \mathrm{~mm}$ in thickness, for in situ tensile testing
(EBSD) analysis, a boundary was defined as any two point pair that had a misorientation angle above $2^{\circ}$. TEM disks were mechanically ground to $100 \mu \mathrm{m}$ and then perforated by a twin-jet electro-polisher at $40 \mathrm{~V} / 18 \mathrm{~mA}$ and $-30{ }^{\circ} \mathrm{C}$. The electrolyte consisted of $10 \%$ perchloric acid and $90 \%$ ethanol. TEM observations were conducted in a FEI Tecnai 20 microscope, operating at $200 \mathrm{kV}$.

\section{Results and Discussion}

\subsection{Microstructures After Heat Treatment and Thermal Simulation}

The microstructure of T24 following the heat treatment was that of the tempered bainite, as observed in Fig. 5. The matrix was comprised of lath bainitic ferrite (see Fig. 5a, b). $M_{23} \mathrm{C}_{6}$ carbides were observed mainly at the GBs of prior austenite, as indicated by the arrows in Fig. 5b. The MX (MC type) precipitates were formed within the lathes and also along the lath boundaries. The observations are consistent with the results reported by previous studies [14-17].

The thermal simulation significantly affects the microstructure, as illustrated in Figs. 6 and 7. A number of martensite/austenite (M/A) islands were formed (see Fig. 6). The retained austenite was the major constituent of the M/A islands. The crystal structure of the ferrite and austenite is body-centered cubic and face-centered cubic,
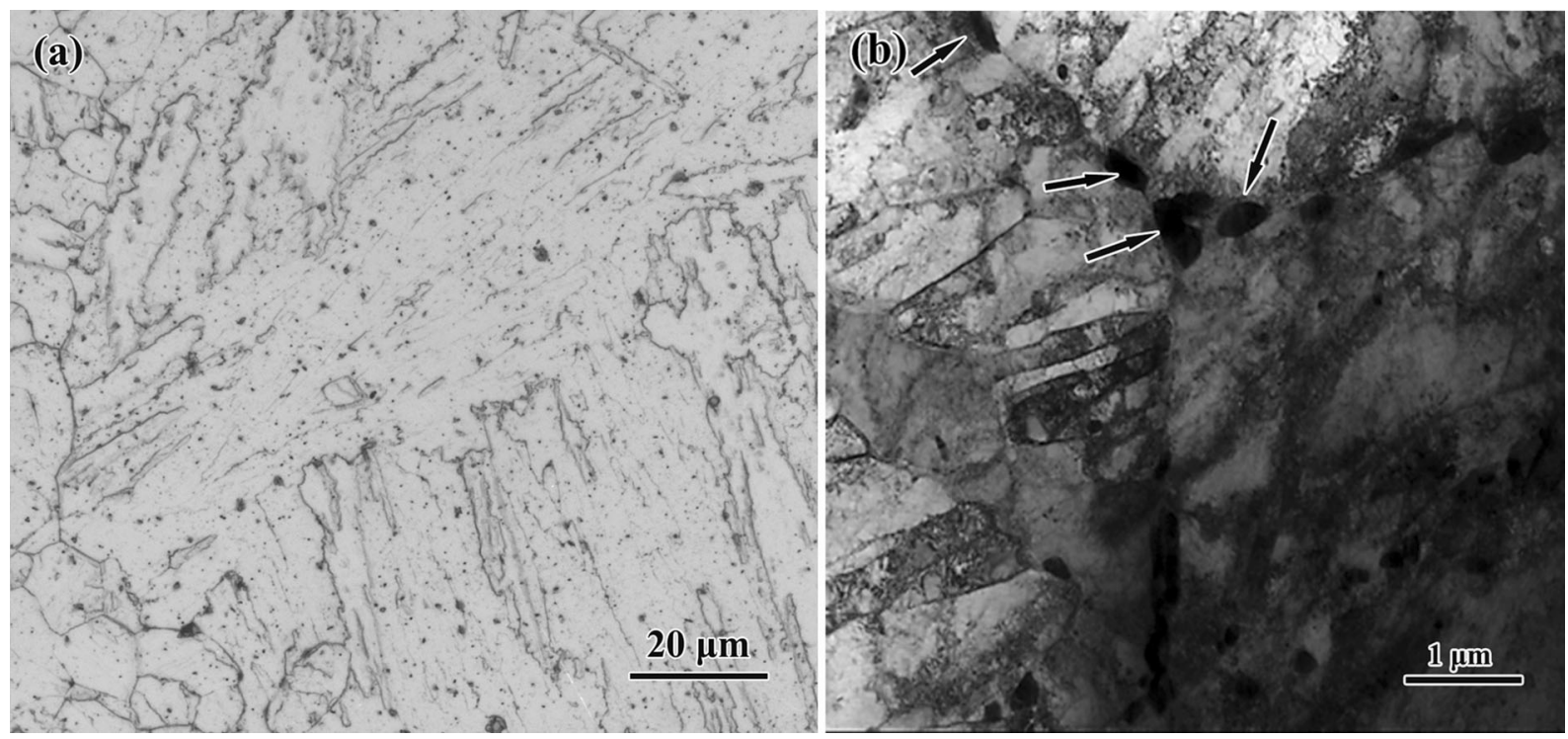

Fig. 5 Initial microstructures of T24 following heat treatment. a Optical micrograph. b TEM micrograph. The $M X$ precipitates at lath boundaries are indicated by arrows 
respectively; thus, the two phases can be exclusively identified by using the EBSD technique. In Fig. 6, an EBSD image clearly shows the ferrite, marked by red color, and the austenite, marked by green color. The retained $\gamma$ phase is primarily distributed along the lath boundaries and the prior austenite GBs. Also, the average size of the retained austenite became larger, approximately $200 \mathrm{~nm}$, as observed in Fig. 7b. Finally, the significant

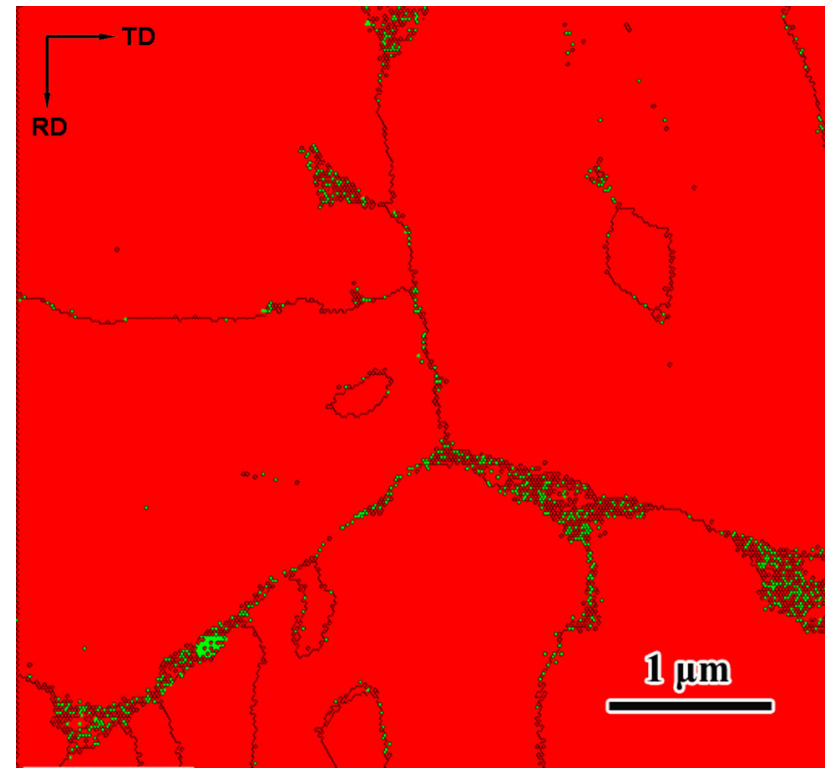

Fig. 6 EBSD image showing the microstructure of T24 following thermal simulation. The ferritic matrix (red color) and retained austenite $(\gamma$ phase, green color) were primarily distributed along lath bainitic ferrite boundaries and the prior austenite GBs grain growth occurred, due to the rapid heating of the specimen to $1350{ }^{\circ} \mathrm{C}$.

\subsection{Microstructural Evolution Near the Grain Boundaries After Stress Relief}

Following stress relaxation testing at $550{ }^{\circ} \mathrm{C}$ for $30 \mathrm{~min}$, the retained blocky austenite was observed to decompose into the ferrite and $\mathrm{Fe}_{3} \mathrm{C}$, as presented in Fig. 8. The newly formed ferritic phase was a softening zone with lower carbon content, where the dislocations were relatively easier to slip (Fig. 8b). Selecting the (11)2) reflection from austenite, the morphology of retained austenite is clearly illustrated in the dark field TEM image (see Fig. 8c). In Fig. 8d, the decomposed $\mathrm{Fe}_{3} \mathrm{C}$ had an average size of approximately $60 \mathrm{~nm}$.

After stress relaxation testing at $550{ }^{\circ} \mathrm{C}$ for $90 \mathrm{~min}$, the retained austenite was continuously decomposed into ferrite and $\mathrm{Fe}_{3} \mathrm{C}$, as observed in Fig. 9. Compared to the specimen tested at $550{ }^{\circ} \mathrm{C}$ for $30 \mathrm{~min}$, the decomposed carbides became larger, approximately $160 \mathrm{~nm}$. The slipping of dislocations was blocked by the carbide at GB.

\subsection{Vickers Hardness}

As stated above, the simulated CGHAZ presented the microstructure of the granular bainite. The average macro Vickers hardness of CGHAZ was 366, and the microhardness of M/A islands at GB was 394, as illustrated in Fig. 10a. On the contrary, for the simulated CGHAZ specimen, following annealing at $550{ }^{\circ} \mathrm{C}$ for $400 \mathrm{~h}$, the
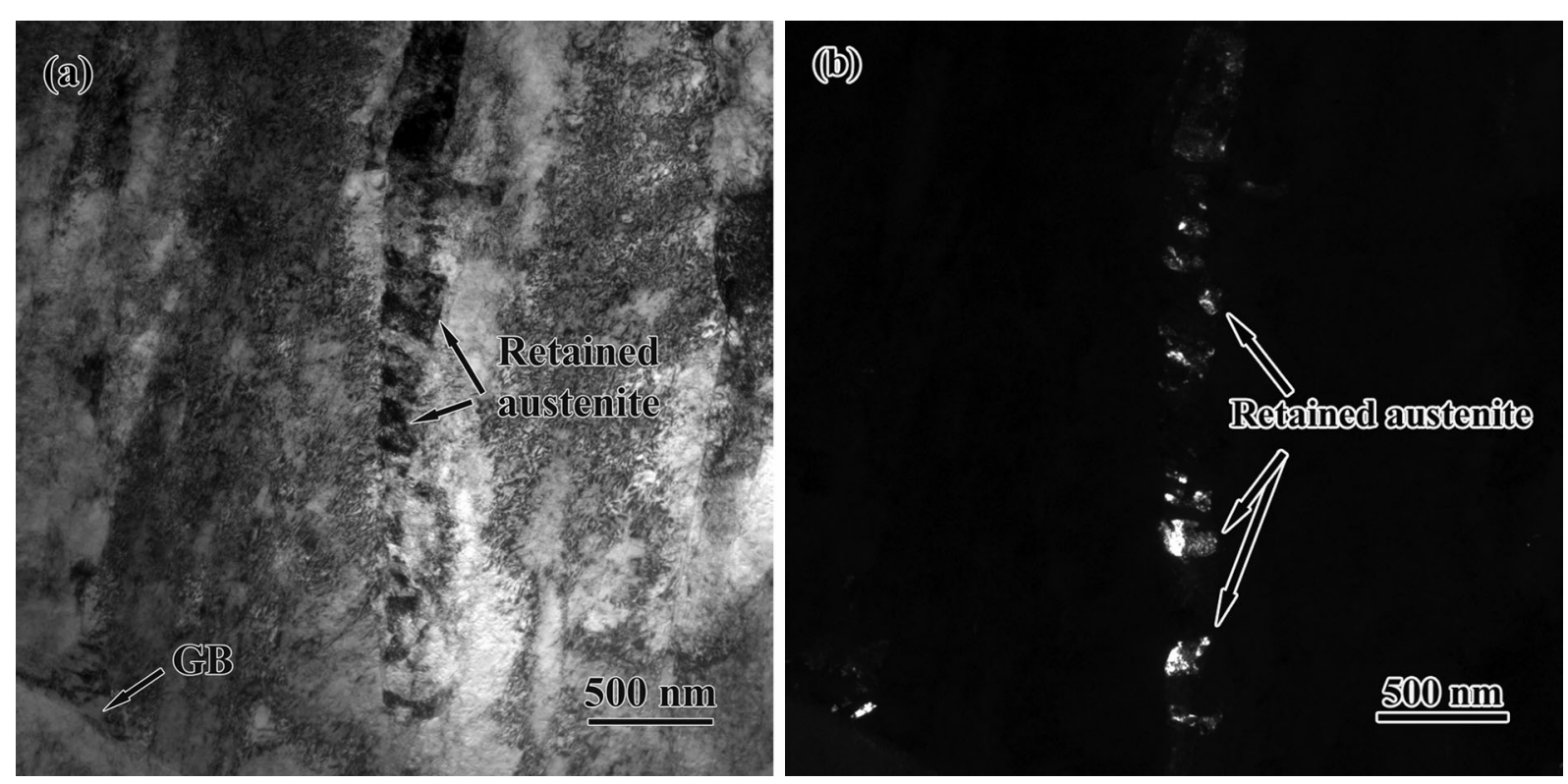

Fig. 7 TEM micrographs of T24 following thermal simulation. a Bright field image showing the M/A islands at GBs. b Bright contrasted phases in dark field image are the retained austenite with a typical size of approximately $200 \mathrm{~nm}$ 

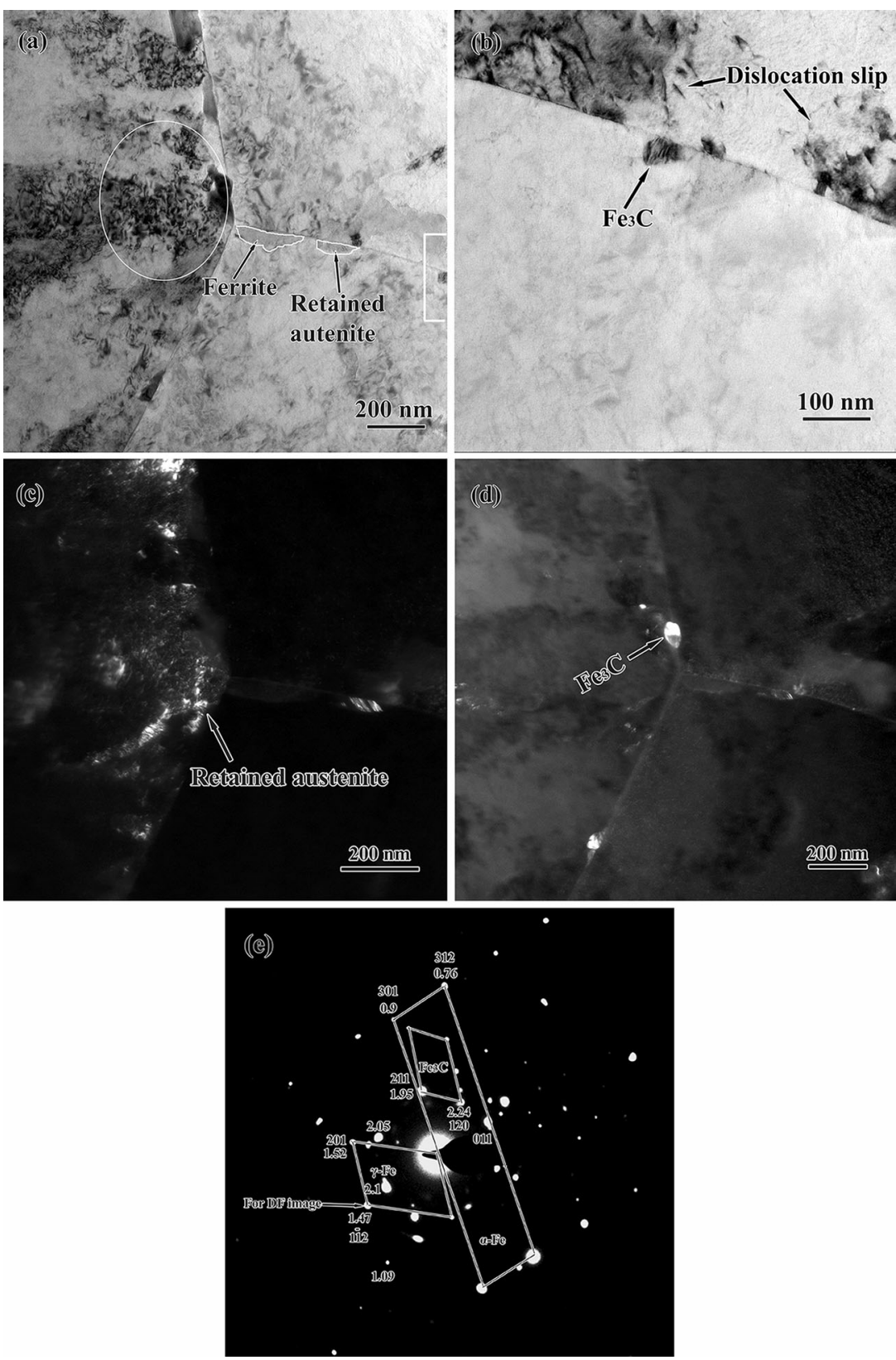

Fig. 8 Microstructures of the specimen following stress relaxation testing at $550{ }^{\circ} \mathrm{C}$ for $30 \mathrm{~min}$. a Bright field image, showing the ferrite and retained austenite. The white frame schematically indicates the area for electron diffraction pattern. b Enlarged image of the white frame of a, showing the morphology of $\mathrm{Fe}_{3} \mathrm{C}$ at $\mathrm{GB}$ and dislocation slipping. c Corresponding dark field image of a showing the morphology of retained austenite. $\mathbf{d}$ Dark field image showing a $\mathrm{Fe}_{3} \mathrm{C}$ particle at GB. e Overlapped electron diffraction pattern originated from the framed area in a. The austenite, ferrite and $\mathrm{Fe}_{3} \mathrm{C}$ were indexed. The (11) reflection from the austenite was selected for taking dark field image $\mathbf{c}$

average hardness of CGHAZ was 367, and the microhardness of M/A islands was 314, as presented in Fig. 10b. By comparing the two specimens, the hardness was maintained to be constant following $400 \mathrm{~h}$ annealing, and the M/A islands had a higher Vickers hardness than the overall hardness. However, the microhardness of M/A islands was significantly decreased following longer annealing time. It is believed that the longer the annealing time, the more austenite decomposes.

\subsection{GB Sliding During Stress Relief}

The specimen with the scratch lines across GBs was examined to identify the GB sliding behavior. Following stress relief testing at $550{ }^{\circ} \mathrm{C}$ for $30 \mathrm{~min}$, the scratch lines still had a straight line and were continuous, as observed in Fig. 11. This implies that no significant GB sliding occurred. Thus, the creep-like GB sliding during stress relief can be excluded as a mechanism for SRC, and it can 


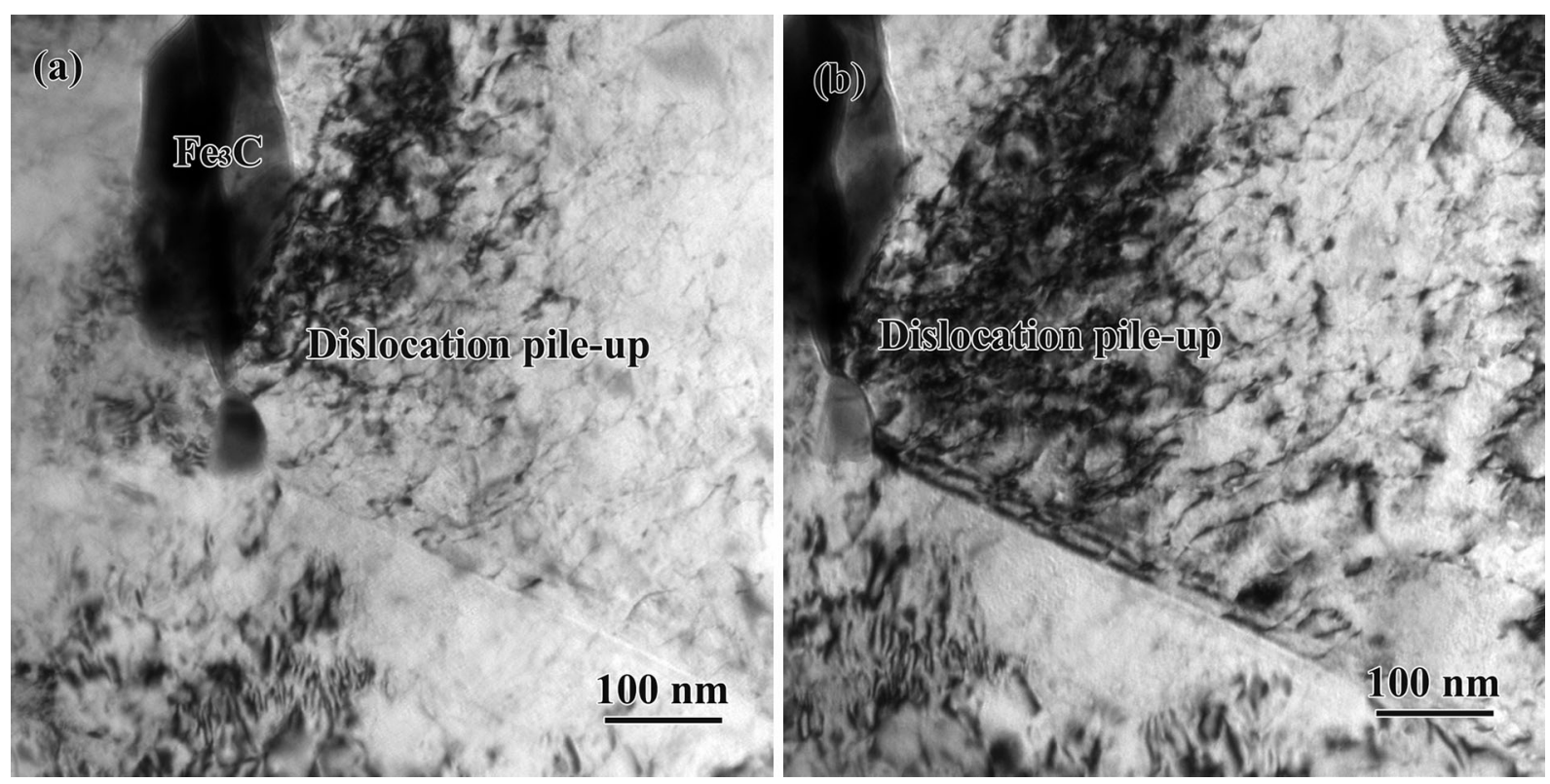

Fig. 9 Microstructures of specimen following stress relaxation testing at $550{ }^{\circ} \mathrm{C}$ for 90 min. a $\mathrm{Fe}_{3} \mathrm{C}$ located at GB. b Dislocation slipping, blocked by a $\mathrm{Fe}_{3} \mathrm{C}$ particle
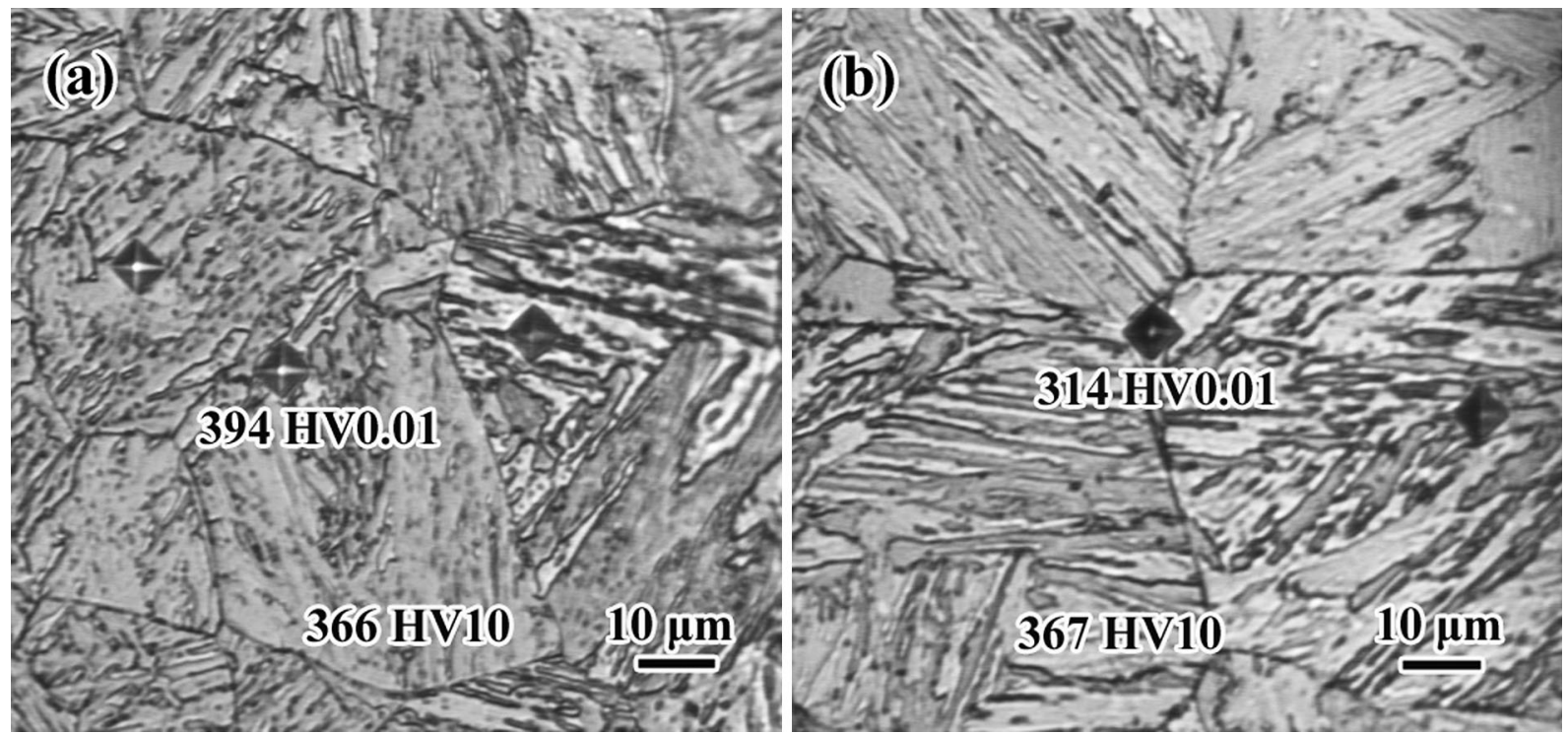

Fig. 10 Values of Vickers hardness and microhardness. a Simulated CGHAZ and M/A islands at GB without annealing. b Simulated specimen following annealing at $550{ }^{\circ} \mathrm{C}$ for $400 \mathrm{~h}$

be considered that other mechanisms may dominate the SRC process.

\subsection{In-Situ Tensile Test}

Usually, the SRC occurs at temperatures above $550{ }^{\circ} \mathrm{C}$. For the specimens annealing at $650{ }^{\circ} \mathrm{C}$, the stress relief behavior is more pronounced. Thus, following thermal simulation, the specimen for in situ tensile testing was annealed at $650{ }^{\circ} \mathrm{C}$ for $10 \mathrm{~h}$. During in situ tensile testing at room temperature, the crack was observed to initiate adjacent a carbide at GB, as observed in Fig. 12a. Further increase of stress caused the crack propagation along GB, as shown in Fig. 12b. Tensile deformation causes plastic strain. However, dislocation slip was hindered by the $M_{3} \mathrm{C}$ carbides, which resulted in the dislocation pile-up and stress concentration at GBs, typically, the triple point junctions. When the stress concentration is sufficiently 


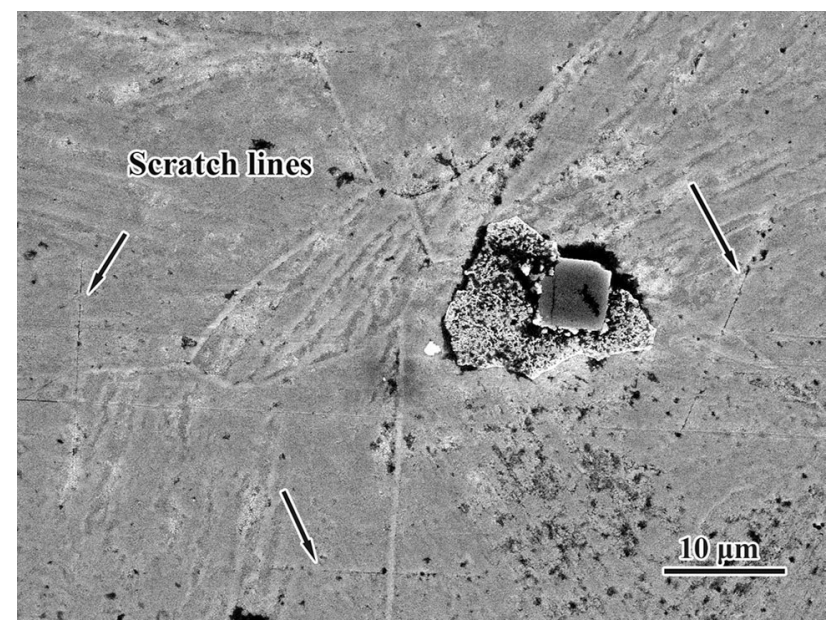

Fig. 11 SEM image showing the straight shaped and continuous scratch lines, as indicated by the white arrows, following stress relief testing at $550{ }^{\circ} \mathrm{C}$ for $30 \mathrm{~min}$. This implies that no GB sliding occurred high, it may result in crack initiation and subsequent propagation.

\section{Discussion and Modeling}

Most of the previous studies suggest that the MX phase precipitates intragranularly to strengthen the grain and that the sulfide precipitates intergranularly or $\mathrm{S}$, as an impurity, aggregates along the GBs to induce the brittle during the process of the stress relief [1]. So, stress relief cannot take place within the grain but along the GBs, and the cracking mechanism is the creep-like GB sliding. However, in the present study, the mechanism of SRC is different. The SRC process is suggested as follows: following the thermal simulation (welding), most of the retained austenite is formed at GBs (see Fig. 13a). During stress relief at
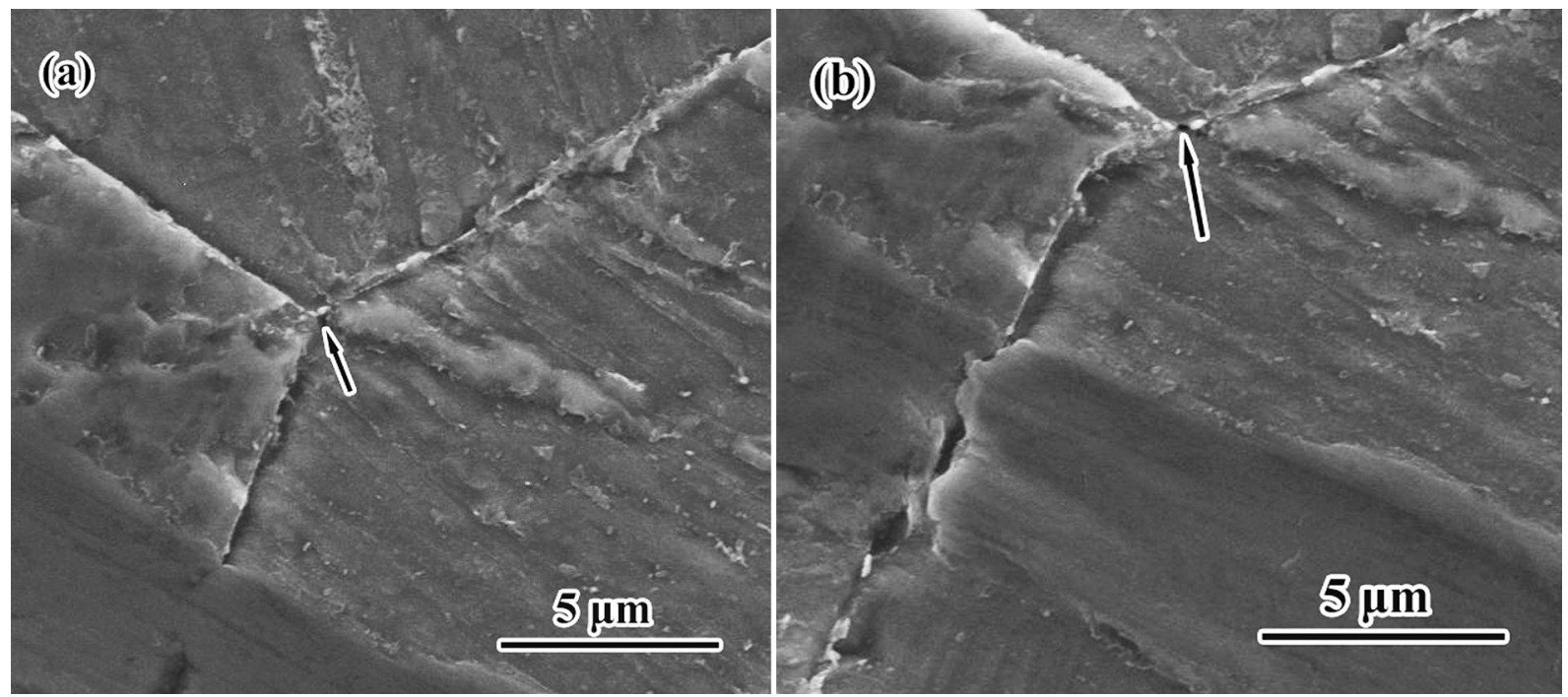

Fig. 12 SEM images showing the crack initiation $\mathbf{a}$ and propagation $\mathbf{b}$, as indicated by the arrows, adjacent to a triple point junction during in situ tensile testing at room temperature. The specimen was annealed at $650{ }^{\circ} \mathrm{C}$ for $10 \mathrm{~h}$
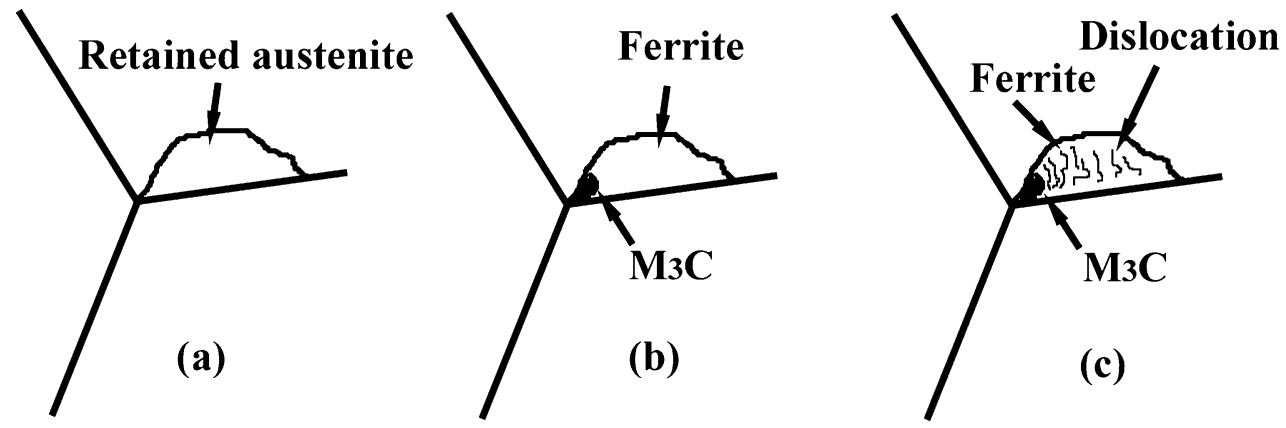

Fig. 13 A schematic drawing showing the cracking mechanism. a Morphology of the retained austenite adjacent a triple point junction. $\mathbf{b}$ The retained austenite decomposes into ferrite and $M_{3} \mathrm{C}$ carbide. $M$ denotes $\mathrm{Fe}, \mathrm{Cr}, \mathrm{Mo}, \mathrm{Nb}$ or $\mathrm{V}$. c Dislocations are initially generated within the relatively soft ferrite. Subsequent dislocation slipping is impeded by the $M_{3} \mathrm{C}$ adjacent the triple point junction, resulting in dislocation pile-up and stress concentration at the triple point junction 
elevated temperatures $\left(550{ }^{\circ} \mathrm{C}\right.$ in the present study), the retained austenite decomposes into $M_{3} \mathrm{C}$ carbide and ferrite (see Fig. 13b). The new ferrite, formed by the decomposition of M/A islands, comprises a softening zone, and the dislocations may be generated in the ferrite adjacent to GBs. The subsequent dislocation slipping is hindered by the $M_{3} \mathrm{C}$ type carbides, which causes the dislocation pile-up and stress concentration at GBs, typically, at triple point junctions. When the stress concentration is sufficiently high, it may result in GB sliding and SRC (see Fig. 13c).

According to Taylor equation [18]:

$\tau=\tau_{0}+\alpha G b \sqrt{\rho}$,

where $\tau$ is the flow stress, $\tau_{0}$ is the stress required to move a dislocation in the absence of other dislocations, $\alpha$ is a dislocation strengthening constant, $G$ is the shear modulus, $b$ is the Burgers vector of slipping dislocation, and $\rho$ is the dislocation density. As $\rho$ increases, the flow stress increases as well, this results in the stress concentration. Fracture toughness $K_{\mathrm{IC}}$ is a material parameter to describe the resistance of the material against fracture, which is closely related to the applied stress and crack length, as follows [19]:

$K_{\mathrm{IC}}=Y \sigma \sqrt{a}$,

where $Y$ is a dimensionless geometry factor, $\sigma$ is the applied stress, $a$ is the length of a crack. In the present study, the stress concentration due to microstructural changes facilitates the crack initiation and growth.

\section{Conclusions}

1. Large M/A islands were distributed along the GBs in the simulated CGHAZ specimen.

2. During stress relief, the retained austenite of the M/A islands along the GBs was decomposed into $M_{3} \mathrm{C}$ carbides and softening ferrite.
3. The creep-like grain boundary sliding was not observed during the stress relief process in the present study. It was indicated that the dislocations are generated within the ferrite, formed by the decomposition of $\mathrm{M} / \mathrm{A}$ islands, adjacent the GBs and subsequent dislocation slipping was hindered by the $M_{3} \mathrm{C}$ carbides. The dislocation pile-up and stress concentration occurs at GBs, typically, at triple point junctions, finally caused the SRC.

Acknowledgements Dr. Yong Yuan thanks the financial support from China Huaneng Group and Huaneng Power International, Inc.

\section{References}

[1] J.G. Nawrocki, J.N. Dupont, C.V. Robino, J.D. Puskar, A.R. Marder, Weld. J. 2, 25s (2003)

[2] N.H. Heo, J.C. Chang, Metall. Mater. Trans. A 42, 3562 (2011)

[3] J.P. Balaguer, Z. Wang, E.F. Nippes, Weld. J. 68, 121 (1989)

[4] J.G. Nawrocki, J.N. Dupont, C.V. Robino, J.D. Puskar, A.R. Marder, Weld. J. 82, 25 (2003)

[5] J.G. Nawrocki, J.N. Dupont, C.V. Robino, I.D. Puskar, A.R. Marder, Weld. J. 79, 355 (2000)

[6] J. Shin, C.J. Mcmahon Jr., Acta Metall. 32, 1535 (1984)

[7] C.A. Hippsley, J.F. Knott, B.C. Edwards, Acta Metall. 28, 869 (1980)

[8] C.A. Hippsley, J.F. Knott, B.C. Edwards, Acta Metall. 30, 641 (1982)

[9] D. Hull, D.E. Rimmer, Philos. Mag. A 4, 673 (1959)

[10] M.V. Speight, J.E. Harris, Met. Sci. 1, 83 (1967)

[11] R. Raj, M.F. Ashby, Acta Metall. 23, 653 (1975)

[12] T.J. Chuang, K.I. Kagawa, J.R. Rice, L.B. Sills, Acta Metall. 27, 265 (1979)

[13] M.W.D. Van Der Brug, E. Van Der Giessen, R.C. Brouwer, Acta Mater. 44, 505 (1996)

[14] R. Raj, Acta Metall. 26, 995 (1978)

[15] W. Bendick, J. Gabrel, B. Hahn, B. Vandenberghe, Int. J. Press. Vessel. Pip. 84, 13 (2007)

[16] Q.B. Yu, G.S. Duan, Iron Steel 43, 68 (2008)

[17] G. Golański, J. Jasak, J. Słania, Kovove Mater. 52, 99 (2014)

[18] M.E. Kassner, Acta Mater. 52, 1 (2004)

[19] X.K. Zhu, J.A. Joyce, Eng. Fract. Mech. 85, 1 (2012) 